\title{
Frequency and Related Factors of Depressive Symptoms Among Elders Who Live in a Residential Home in Istanbul
}

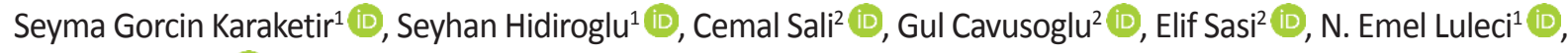 \\ Melda Karavus ${ }^{1}$ (D) \\ ${ }^{1}$ Marmara University, Faculty of Medicine, Deparment of Public Health, Istanbul, Turkey. \\ ${ }^{2}$ Marmara University, Faculty of Medicine, Medical Student, Istanbul, Turkey. \\ Correspondence Author: Seyma Gorcin Karaketir \\ E-mail: gorcin_eseyma@hotmail.com \\ Received: 30.01.2018 Accepted: 30.03.2018
}

\begin{abstract}
Objective:The elderly population, defined as $\geq 65$ years old, is increasing with time in society. Depressive symptoms in old age lead to worsening of physical and cognitive abilities. This study investigated the prevalence of depressive symptoms in elderly people living in a residential home in Istanbul and factors affecting this indication.

Methods:The study was conducted in a descriptive and cross-sectional manner. The questionnaire, which included sociodemographic questions and inquiries on factors affecting depression, Geriatric Depression Scale Short Form-15 (GDS-15), and Mini-Mental test, was administered to 77 elderly people.

Results:Twenty-nine of the participants were females and 48 were males, with a mean age of $75.9 \pm 8.2$ years. The mean GDS-15 score of the elderly was $4.04 \pm 3.42$. Concerns regarding leaving the residential home, low telephone call frequency, persistent physical illness, and inability to complete self-care activities were significantly associated with depressive symptoms.

Conclusion:Depressive symptoms are common in the elderly living in residential homes. This occurrence is closely related to social support and health status. Further studies are warranted to determine if factors associated with such symptoms are risk factors for depression.

Keywords: Social Support; Depression; Self Care; Health Status
\end{abstract}

\section{INTRODUCTION}

The average life span has been extended due to improvements in the health field and in living conditions (1). The proportion of the elderly population (defined as $\geq 65$ years) in the general population is $21 \%-26 \%$ in countries such as Japan and Germany, and $8.3 \%$ in Turkey in 2016 (2). Depression causes "loss of ability" and "mortality" in the elderly and worsens the prognosis of accompanying health problems. It also causes increased loss of function compared with diseases such as diabetes and hypertension. However, depression in old age is less well known to physicians, and the diagnosis is difficult. Depression is generally believed to be related to the aging process or other medical conditions (3). Furthermore, it is more prevalent in the elderly who live in residential homes than in those living elsewhere; therefore, the former constitutes a layer of society that is more fragile and requires additional social support $(4,5)$. Although many studies have described varying ratios, the prevalence of depression in individuals aged $\geq 65$ years is up to $40 \%$ in those living in residential homes and approximately $8 \%-$ $15 \%$ in the general population (6).
Many factors affect the prevalence of depression in the elderly. These factors may be person-specific reasons, inadequate social support, or factors related to an institution and its residents. Ryden et al. found an inverse relationship between existence of depressive symptoms and levels of satisfaction from a residential home (7). Zunzunegui reported that low education level, being a female, being widowed, and having low social support for their children are associated with depression in 1284 people from a study population in Spain (8). A study conducted by Sütoluk et al. in Adana residential homes revealed that non-housewives and individuals without hobbies were more at risk for depression than other residents (9). In the study by Kavakçı, depression was commonly found in women and in individuals with cognitive impairments. Additionally, male sex, duration of education, and smoking are negatively correlated with depression (10). Hagerty and Williams reported that loneliness, a lack of sense of belonging, and social support are factors affecting the development of depression (11).

The fact that many of these causes are commutable factors and the incidence of depressive symptoms is high in the elderly make depression a public health problem. 
This study aimed to determine the prevalence of depression and investigate the factors affecting depression at a residential home in İstanbul.

\section{METHODS}

Descriptive studies were conducted from October to December 2016 on individuals living in a residential home in Istanbul. Permission was obtained from the director of the residential home. A total of 165 residential home residents were invited to participate in the study; 130 individuals had no mental or physical problems such as Alzheimer's, dementia, or paralysis that prevented them from answering questions. Thirty-five elderlies with impaired function required care due to their cognitive or physical illness and stayed in a rehabilitation center connected to the residential home. Twenty-eight people refused to participate in the study, and 25 were not included in the study because they did not pass the Mini-Mental test. As a result, we had a final population of 77 elderlies, who provided their informed consent. The participation rate was $59 \%$. This cross-sectional study was considered descriptive owing to its low participation rate. However, the nature of the work is a condition that is expected with a limitation. The residents were assessed through question forms using the Mini-Mental test, Geriatric Depression Scale Short Form-15 (GDS-15), and questionnaire about factors affecting depression including sociodemographic questions. The Mini-Mental test is divided into four main sections: orientation, recording memory, attention and calculation, and recall and language. The short form of GDS-15 was administered, which had 15 questions that included yes/no answers (Table 1). Five questions (question number; $1,5,7,11$, and 13 ) were positive and others were negative. A total score of $\geq 6$ is significant for the diagnosis of depression (12). A total of 33 sociodemographic questions were in the questionnaire. Such questions were about the sociodemographic characteristics of the elderly, the way in which they perceive themselves, their health and environment, their relatives, and relations with the residents of rest homes. All questions were prepared by examining the relevant literature $(5,9,10,13)$.

Table 1. Geriatric Depression Scale (Short Form)

1. Are you basically satisfied with your life?

2. Have you dropped many of your activities and interests?

3. Do you feel that your life is empty?

4. Do you often get bored?

5. Are you in good spirits most of the time?

6. Are you afraid that something bad is going to happen to you?

7. Do you feel happy most of the time?

8. Do you often feel helpless?

9. Do you prefer to stay at home, rather than going out and doing things?

10. Do you feel that you have more problems with memory than most?

11. Do you think it is wonderful to be alive now?

12. Do you feel worthless the way you are now?

13. Do you feel full of energy?

14. Do you feel that your situation is hopeless?

15. Do you think that most people are better off than you are?
Data were collected between October 10-30, 2016, and the questionnaire was administered in person. The approval of the ethics committee was obtained in October 2016 from the ethics committee of the medical faculty of the university to which the researchers are affiliated.

\subsection{Statistical Analysis}

For the statistical evaluation of the data, percentages, mean numbers, standard deviations, and figures were used. Furthermore, the Mann-Whitney $U$ test, Chi-square test, Fisher exact test, and Kruskal-Wallis variance analyses were also employed. For statistical significance, $p<0.05$ was considered.

\section{RESULTS}

Sociodemographic characteristics: The 77 elderlies who constituted the sample of our study comprised 29 (37.7\%) females and $48(62.3 \%)$ males. The mean age was $75.9 \pm$ 8.2 (minimum; 60 years, maximum; 95 years). The majority of the participants was widowed $(58.4 \%)$, had children (71.4\%).

Twenty-two of the elderlies (28.6\%) were depressive and 55 were normal (71.4\%). Depressive symptoms were assessed according to variables reported in the table and reported as factors that may be associated with depression in the literature. In univariate analysis, low telephone call frequency, concerns of leaving the residential home, persistent physical illness, and inability to complete selfcare activities were significantly associated with existence of depressive symptoms ( $p<0.05$; Table 2).

The mean GDS-15 score of the elderly was $4.04 \pm 3.42$ (minimum; 0, maximum; 14). When the average of the scores was examined according to the variables, GDS15 scores were found to be higher in those with low telephone call frequency $(p<0.01)$, who were concerned about leaving the residential home $(p<0.05)$, who felt very sick $(p<0.01)$, and who were continuously ill ( $p<$ 0.05; Table 3). When other factors were examined, no statistically significant difference was found between the mean scores $(p>0.05)$.

\section{DISCUSSION}

Many risk factors have been identified for depression in the elderly. Various studies showed that being a woman, having low socioeconomic status, loss of partner, living alone, inadequate physical activity, inadequate social support, experiencing sleep disorders, having cognitive or chronic diseases, lack of ability to perform self-care activities, reluctance to participate in social activities, and receiving no visits are factors that contribute to depression $(5,9,13,14)$. Therefore, it is important to target individuals who lack social support and have risk factors in interventions. 
Table 2. Comparison of Depressive Symptom Inventory with One-Way Analysis by Factors Affected by Depression

\begin{tabular}{|c|c|c|c|c|c|c|}
\hline & & \multicolumn{4}{|c|}{ Depression } & \multirow[b]{3}{*}{ p } \\
\hline & & \multicolumn{2}{|c|}{ Depressive } & \multicolumn{2}{|c|}{ Normal } & \\
\hline & & n & $\%$ & n & $\%$ & \\
\hline \multicolumn{2}{|l|}{ Age (Mean \pm Standart Deviation) } & \multicolumn{2}{|c|}{$75.23 \pm 7.3$} & \multicolumn{2}{|c|}{$76.20 \pm 8.6$} & $0.693^{c}$ \\
\hline \multirow{2}{*}{ Gender } & Female & 9 & 31.0 & 20 & 69.0 & \multirow{2}{*}{$0.710^{\mathrm{a}}$} \\
\hline & Male & 13 & 27.1 & 35 & 72.9 & \\
\hline & Yes & 17 & 30.9 & 38 & 69.1 & \\
\hline Having Cnilaren & No & 5 & 22.7 & 17 & 77.3 & $0.4 / 3^{\circ}$ \\
\hline & No & 3 & 50.0 & 3 & 50.0 & \\
\hline Soclal Insurance & Yes & 19 & 26.8 & 52 & 73.2 & $0.345^{\circ}$ \\
\hline & No training & 3 & 30.0 & 7 & 70.0 & \\
\hline Education & Primary school & 9 & 27.3 & 24 & 72.7 & \\
\hline & Middle school and higher & 10 & 39.4 & 24 & 70.6 & $0.976^{2}$ \\
\hline & Low & 9 & 39.1 & 14 & 60.9 & \\
\hline Income Level of Perception & Middle & 11 & 23.9 & 35 & 76.1 & $0.407^{\mathrm{a}}$ \\
\hline & High & 2 & 25.0 & 6 & 75.0 & \\
\hline Reasons For Coming To Residental & Own wish & 19 & 29.2 & 46 & 70.8 & \\
\hline Home & involuntary & 3 & 25.0 & 9 & 75.0 & $0.163^{\circ}$ \\
\hline & No & 12 & 31.6 & 26 & 68.4 & \\
\hline Compliance problem with children & Yes & 5 & 21.7 & 18 & 78.3 & $0.406^{\mathrm{a}}$ \\
\hline & Several times a week & 12 & 32.6 & 26 & 68.4 & \\
\hline Telephone Call Frequency & Several times a month & 8 & 42.1 & 11 & 57.9 & \\
\hline & Once a year or never & 2 & 10.0 & 18 & 90.0 & $0.023^{\mathrm{a}}$ \\
\hline & Several times a week & 6 & 20.8 & 16 & 59.3 & \\
\hline Visitor Status & Several times a month & 5 & 23.8 & 16 & 76.2 & \\
\hline & Once a year or never & 11 & 40.7 & 16 & 59.3 & $0.215^{\mathrm{a}}$ \\
\hline & Several times a week & 6 & 15.8 & 32 & 84.2 & \\
\hline Homecoming Frequency & Several times a month & 6 & 40.0 & 9 & 60.0 & \\
\hline & Once a year or never & 10 & 41.7 & 14 & 58.3 & $0.051^{\mathrm{a}}$ \\
\hline & Less than one year & 1 & 9.1 & 10 & 90.9 & \\
\hline Length or Live in Residental Home & Longer than one year & 21 & 31.8 & 45 & 68.2 & $0.163^{\circ}$ \\
\hline & Partially satisfied & 12 & 33.3 & 24 & 66.7 & \\
\hline Satıstactıon From IVlanagement & Fully satisfied & 10 & 24.4 & 31 & 75.6 & $0.386^{\mathrm{d}}$ \\
\hline & Partially satisfied & 9 & 39.1 & 14 & 60.9 & \\
\hline Satistaction rrom Personnel & Fully satisfied & 13 & 24.1 & 41 & 75.9 & $0.144^{\circ}$ \\
\hline Satisfaction With The Physical & Partially satisfied & 5 & 29.4 & 12 & 70.6 & \\
\hline Condition of The Institution & Fully satisfied & 17 & 28.3 & 43 & 71.7 & $0,931^{\text {a }}$ \\
\hline & Not at all satisfied & 3 & 33.3 & 6 & 66.7 & \\
\hline Satisfaction From Residents & Partially satisfied & 14 & 31.8 & 30 & 68.2 & \\
\hline & Fully satisfied & 5 & 20.8 & 19 & 79.2 & $0.597^{a}$ \\
\hline & Not enough & 7 & 30.4 & 16 & 69.6 & \\
\hline Institutional social Activity & Enough & 15 & 27.8 & 39 & 72.2 & $0.813^{\circ}$ \\
\hline The Desire To Participate In The & Reluctant & 7 & 36.8 & 12 & 63.2 & \\
\hline Ine Desire lo Participate in Ine & Sometimes willing & 9 & 30.0 & 21 & 70.0 & \\
\hline Activities & Always willing & 6 & 21.4 & 22 & 78.6 & $0.505^{\mathrm{a}}$ \\
\hline Residental Home Residents' To & Strange or anyone & 10 & 35.7 & 18 & 64.3 & \\
\hline 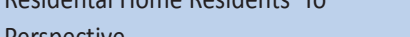 & Friend & 9 & 27.3 & 24 & 72.7 & $0.476^{\mathrm{a}}$ \\
\hline Perspective & Family and ally & 3 & 18.8 & 13 & 81.3 & \\
\hline The Concern About Leaving From The & Sometimes & 6 & 60.0 & 4 & 40.0 & \\
\hline Residental Home & Never & 16 & 23.9 & 51 & 76.1 & $0.018^{b}$ \\
\hline & Healthy & 7 & 19.3 & 29 & 80.7 & \\
\hline Feeling Healthy & Normal & 3 & 25.0 & 9 & 75.0 & \\
\hline & Sick & 12 & 41.4 & 17 & 58.6 & $0.144^{\mathrm{a}}$ \\
\hline & No & 5 & 16.1 & 26 & 83.9 & \\
\hline Contınuous Physical iliness & Yes & 17 & 37.0 & 29 & 63.0 & $0.047^{\circ}$ \\
\hline & less than one year & 0 & 0 & 2 & 100.0 & $0528^{\mathrm{b}}$ \\
\hline Duration Ot Physical IIIness & Longer than one year & 17 & 37.8 & 28 & 62.2 & $0.528^{\circ}$ \\
\hline & Single & 1 & 10.0 & 9 & 90.0 & \\
\hline The Sharıng of Ine Room & Two or more people & 21 & 31.3 & 46 & 68.7 & $0.265^{\circ}$ \\
\hline Fear of Falling And Rone Fracture & Yes & 9 & 42.9 & 12 & 57.1 & 0089 а \\
\hline Fear of ralling And Bone rracture & No & 13 & 23.2 & 43 & 76.8 & $0.089^{\circ}$ \\
\hline & Yes & 8 & 34.8 & 15 & 65.2 & $0.431^{\text {a }}$ \\
\hline Sleeping Problem & No & 14 & 25.9 & 40 & 74.1 & $0.431^{\mathrm{d}}$ \\
\hline Chronic Pain & No & 17 & 28.8 & 42 & 71.2 & \\
\hline Chronic Pain & Yes & 5 & 27.8 & 13 & 72.2 & $0.932^{\circ}$ \\
\hline & Yes & 5 & 33.3 & 10 & 66.7 & \\
\hline Urınary Problems (Jam etc.) & No & 17 & 27.4 & 45 & 72.6 & $0.752^{b}$ \\
\hline Defecation Problems (Constipation & Yes & 9 & 42.9 & 12 & 57.1 & \\
\hline etc.) & No & 13 & 23.2 & 43 & 76.8 & $0.089^{a}$ \\
\hline Roing colf-caro & Not exactly & 6 & 60.0 & 4 & 40.0 & $0028^{b}$ \\
\hline Doing selt-care & Exact & 16 & 23.9 & 51 & 76.1 & 0.028 \\
\hline & Yes & 5 & 50.0 & 5 & 50.0 & \\
\hline Mobility & No & 17 & 25.4 & 50 & 74.6 & $0.138^{\circ}$ \\
\hline
\end{tabular}

${ }^{a}$ Chi-Square test. ${ }^{b}$ Fisher's exact test. ${ }^{c}$ Mann Whitney $U$ test. 
Table 3. Comparisons of Factors Related to Depression according to GMS Score's Mean

\begin{tabular}{|c|c|c|c|c|c|}
\hline & \multicolumn{4}{|c|}{ GMS Total Score } \\
\hline & & $n$ & $\%$ & $\begin{array}{l}\text { Mean(Std. } \\
\text { deviation) }\end{array}$ & $\mathrm{p}$ \\
\hline \multirow{5}{*}{$\begin{array}{l}\text { Telephone Call } \\
\text { Frequency }\end{array}$} & Everyday & 20 & 26.0 & $3(0.3)$ & \multirow{5}{*}{$0.002^{d}$} \\
\hline & $\begin{array}{l}\text { Several times } \\
\text { a week }\end{array}$ & 18 & 23.4 & $2.17(0.6)$ & \\
\hline & $\begin{array}{l}\text { Several times } \\
\text { a month }\end{array}$ & 20 & 26.0 & $4.75(0.7)$ & \\
\hline & Once a year & 17 & 22.1 & $6.59(4.1)$ & \\
\hline & Never & 2 & 2.6 & $2.5(0.7)$ & \\
\hline \multirow{3}{*}{$\begin{array}{l}\text { The Concern } \\
\text { About Leaving } \\
\text { From The } \\
\text { Residental Home }\end{array}$} & Yes & 3 & 3.9 & $8.67(2.5)$ & \multirow{3}{*}{$0.045^{c}$} \\
\hline & Sometimes & 7 & 9.1 & $5.29(4.5)$ & \\
\hline & Never & 67 & 87.0 & $3.7(3.1)$ & \\
\hline \multirow[t]{5}{*}{ Feeling Healthy } & Very healthy & 7 & 9.1 & $1.86(2.8)$ & \multirow{5}{*}{$0.020^{d}$} \\
\hline & Healthy & 35 & 45.5 & $2.94(2.4)$ & \\
\hline & Normal & 3 & 3.9 & $4(2.6)$ & \\
\hline & Sick & 31 & 40.3 & $5.45(3.5)$ & \\
\hline & Very sick & 1 & 1.3 & . & \\
\hline \multirow{2}{*}{$\begin{array}{l}\text { Continuous } \\
\text { Physical Illness }\end{array}$} & No & 31 & 40.3 & $2.87(2.5)$ & \multirow[t]{2}{*}{$0.016^{c}$} \\
\hline & Yes & 46 & 59.0 & $4.83(3.7)$ & \\
\hline
\end{tabular}

c Mann Whitney $U$ test. ${ }^{d}$ Kruskal Wallis test.

In a study conducted in Turkey, the prevalence of depressive disorder (major + minor) in the general population was $9 \%$ (15). Depression occurs in approximately $15 \%$ of patients $>65$ years old who apply for a doctor for various reasons and $25 \%$ in residential homes abroad (16). In a study conducted in Turkey, $34 \%$ of the elderly living in their own homes had depression, whereas $48 \%$ of those living in residential homes had depression (14). Despite the low rates of depression in prevalence studies, which are generally diagnosed in a structured manner in accordance with standard clinical diagnostic criteria, depression rates were high in studies using scales that diagnosed at the level of symptoms (5). In this study, the prevalence of depression was found to be $28.6 \%$ with GDS as a diagnostic scale. Harris et al. found a $23.8 \%$ similarity in our study of depression to our study of GDS in the UK (17). Şahin et al. compared the prevalence of depression among those living in residential homes and those living in their own homes in a study in Edirne. The prevalence among those living in residential homes was found to be $48.1 \%$ (14). In Şahin's study, no information was provided regarding the inclusion of elderly people with loss of function due to physical illnesses (14). We did not include patients who were directed to a rehabilitation center owing to cognitive or physical illness; therefore, we possibly found the prevalence of depression to be lower despite using the same scale. In a survey conducted by Demet et al. in a residential home, the prevalence of depression was found to be $35.9 \%(5)$. This difference may be due to the fact that $37.9 \%$ of the respondents in the rehabilitation center consisted of the elderly of low socioeconomic status. The prevalence of depression found in a study by Kavakçı et al. involving 3039 individuals of 55 years old was $13.6 \%$ (10). Considering that their study sample was not from a residential home and comprised a younger group, a lower prevalence of depression may have been found in our study. The prevalence of depression was $48 \%$ among the elderly in some residential homes. This percentage indicates that the significantly high scores from the GDS were from insufficient social support for the elderly, and depressive symptoms were overlooked. Interventions would be appropriate in this regard. When we considered the variables related to depression, we found a significant difference between the frequency of telephone calls and depression in our study. Bekaroğlu et al. found that the lack of care is a risk factor for depression in the elderly at residential homes, and this finding was also confirmed in our study (18).

We found an association between depression and anxiety of withdrawal from the residential home. Demet et al. also noted that depressive symptoms were more frequent in the elderly who were concerned about leaving the residential home, and this finding was consistent with that of the literature (5).

When health status and effects of mobility on depression were examined, results revealed that depressive symptoms were more frequent in those who stated that they had persistent physical illness and were unable to perform self-care activities. Şahin et al. demonstrated that physical health problems increase the prevalence of depression in the elderly (14). According to our findings, the presence of physical illness was related to depression.

Linden et al. detected depression in $50 \%$ of patients being examined by psychiatrists after evaluation and treatment by a physician (19). For this reason, physicians may be advised to assess and screen elderly patients who have physical problems for depression. Kurtoğlu reported that $77 \%$ of the elderly who were diagnosed with depression had a disability. Valvanne and Tilvis found that depression is associated with loss of health and function in the elderly. Disability, health problems, and inability to complete selfcare activities can both be the cause and consequence of depression. Considering that we are unsure about temporality of the factors we investigated and depression, the relationships we found may not be causal.

Factors such as sex (14), educational status $(8,20)$, marital status (8), social insurance, and income (5), which are defined as risks for the formation of depression in the literature, were not effective indicators in our study.

\section{CONCLUSION}

As a result, depressive symptoms in elderly living in residential homes reached significant levels, which were related to inadequate self-care, concern about leaving from the residential home, low telephone call frequency, and persistent physical illness. The risk of becoming depressed 
among the elderly residing in residential homes may be high; therefore, health care providers should evaluate such patients.

Conflict of Interest: No conflict of interest was declared by the authors.

Financial Disclosure: The authors declared that this study has received no financial support.

\section{REFERENCES}

[1] Kontis V, Bennett JE, Mathers CD, Li G, Foreman K, Ezzati $M$. Future life expectancy in 35 industrialised countries: projections with a Bayesian model ensemble, April 2017. The Lancet. 2017; 389(10076):1323-1335.

[2] Turkish Statistical Institute. Addressed based population recording system, 2016. [Internet] Available from: URL: http://www.turkstat.gov.tr/PreHaberBultenleri.do?id=24638. Accessed 19.08.2017. 2016.

[3] Kok RM, Heeren TJ, Nolen WA. Continuing treatment of depression in the elderly: a systematic review and metaanalysis of double-blinded randomized controlled trials with antidepressants. Am J Geriatr Psychiatry. 2011;19(3):249-255.

[4] Bagley H, Cordingley L, Burns A, Mozley CG, Sutcliffe C, Challis $D$, Huxley P. Recognition of depression by staff in nursing and residential homesi, December 2001. J Clin Nurs. 2000;9(3):445450.

[5] Demet MM, Taşkin EO, Deniz F, Karaca N, Icelli I. Depressive symptomatology among elderly residential home residents in Manisa: Prevalence and related risk factors. Turkish J Psychiatry. 2002;13(4):290-299.

[6] Leon FG, Ashton AK, D'Mello DA, Dantz B, Hefner J, Matson GA, Montano B, Pradko JF, Sussman N, Winsberg B. Depression and comorbid medical illness: therapeutic and diagnostic challenges. J Fam Pract. 2003;Suppl:19-33.

[7] Ryden MB, Gross CR, Savik K, Snyder M, Lee Oh H, Jang YP, Wang JJ, Krichbaum KE. Development of a measure of resident satisfaction with the nursing home. Res Nurs Health. 2000;23(3):237-245.

[8] Zunzunegui MV, Beland F, Otero A. Support from children, living arrangements, self-rated health and depressive symptoms of older people in Spain. Int J Epidemiol. 2001;30(5):1090-1099.
[9] Sütoluk Z, Demirhindi H, Savaş N, Akbaba M. Prevalence and causes of depression among elders who live in residential homes in Adana. Türk Geriatri Dergisi. 2004;7(3):148-151.

[10] Kavakcı Ö, Bilici M, Çam G, Ülgen M. Prevalence of depression and cognitive impairment in old age in Trabzon. Anatolian J Psychiatry. 2011;12(4):258-265.

[11] Hagerty BM, Williams A. The effects of sense of belonging, social support, conflict, and loneliness on depression. Nursing Res. 1999;48(4):215-219.

[12] Ertan T, Bugay G, Eker E. Validity and reliability of short versions of Geriatric Depression Scale in Turkish elderly population: GDS-15, GDS-10, GDS-4. In: IIlkay E, Kulaksızoğlu IB, Sivrioğlu $Y$, Tezcan V, Yazgan Ç, editors. Poster session presented at: Excellence in clinical practice, 5th National Geropsychiatry Symposium; 2004 Jun 10-12; Istanbul, Turkey. (in Turkish).

[13] Tufan A, Bahat G, Karan M. The Prevalence of Depressive Symptoms and Risk Factors among Older Adults Admitted to the Geriatrics Outpatient Clinic: A Natural Result of Normal Aging or Not. J Gerontol Geriatr Res. 2016;5(338):2.

[14] Şahin EM, Yalçın M. Comparing the incidences of depression at the elderly living in nursing home or at their own homes. Turkish Journal of Geriatrics. 2003;6(1):10-13.

[15] Kalaça S. Mental Health Problems - Brief PHQ-r (KISA) Survey, In:Ünal B, Ergör G, Horasan GD, Kalaça S, Sözmen K, editors. Chronic Diseases And Risk Factors Survey. Ankara: Republic of Turkey Ministry of Health; 2013.p.235.

[16] NIH consensus conference. Diagnosis and treatment of depression in late life. JAMA. 1992;268(8):1018-1024.

[17] Harris T, Cook DG, Victor C, Rink E, Mann AH, Shah S. Predictors of depressive symptoms in older people-a survey of two general practice populations. Age Ageing. 2003;32(5):510-518.

[18] Bekaroglu M, Uluutku N, Tanriover S, Kirpinar I. Depression in an elderly population in Turkey. Acta Psychiatr Scand. 1991;84(2):174-8.

[19] Linden M, Borchelt M, Barnow S, Geiselmann B. The impact of somatic morbidity on the Hamilton Depression Rating Scale in the very old. Acta Psychiatr Scand. 1995;92(2):150-154.

[20] Osborn DP, Fletcher AE, Smeeth L, Stirling S, Bulpitt CJ, Breeze E. Factors associated with depression in a representative sample of 14217 people aged 75 and over in the United Kingdom: results from the MRC trial of assessment and management of older people in the community. Int J Geriatr Psychiatry. 2003;18(7):623-630.

How to cite this article: Karaketir S. G., Hidiroglu S., Sali C., Cavusoglu G., Sasi E., Luleci N.E., Karavus M. Frequency and Related Factors of Depressive Symptoms Among Elders Who Live in a Residential Home in Istanbul. Clin Exp Health Sci 2019; 9: 112-116. DOI: 10.33808/ clinexphealthsci.564163 